\title{
The Comparison of Quantitative Evaluation Results of the MPS SPECT/CT and Coronary Angiography: Determining the Most Valuable Quantitative Evaluation Score
}

\author{
MPS SPECT/BT Kantitatif Değerlendirme Sonuçlarının Koroner Anjiyografı Sonuçları ile \\ Karşılaştırılması: En Değerli Kantitatif Değerlendirme Skorunun Belirlenmesi
}

\author{
(1) Nazlı Pınar Karahan Şen', (D) Recep Bekis', (1) Bihter Şentürk2, (1) Bahri Akdeniz² \\ I Dokuz Eylül University Faculty of Medicine, Department of Nuclear Medicine, Izmir, Turkey \\ 2Dokuz Eylül University Faculty of Medicine, Department of Cardiology, Izmir, Turkey
}

\begin{abstract}
Objectives: This study aimed to determine the most important perfusion score in patient selection for coronary angiography (CA) by quantitatively evaluating myocardial perfusion scintigraphy (MPS).

Methods: Patients who underwent MPS single-photon emission computerized tomography/computed tomograph imaging in our clinic between December 2017 and January 2019, without coronary artery disease (CAD) history, followed by CA were included in the study. CA was considered positive when there is a stenosis of $70 \%$ or more in at least one coronary vessel. The summed stress score, rest score, and differential score; total perfusion deficit (TPD); and the defect's extent obtained from non-attenuation-corrected (NC) and attenuation-corrected (AC) images of 80 patients were evaluated using the Mann-Whitney $U$ test. A p value of $<0.05$ was considered significant. Receiver operating characteristic (ROC) analysis was performed.

Results: The scores obtained from NC and AC images showed a significant difference between the two groups for all scores except for the extent and TPD scores at rest from AC images. The applied ROC curves' highest diagnostic value was determined as the TPD score at stress (TPDS) obtained from NC images (area under the curve: $0.880,95 \%$ confidence interval, $0.807-0.952, p<0.001$ ). The cut-off value obtained for the TPDS from the ROC curve was found to be 5.5 .

Conclusion: The scores obtained from NC images have more power to detect CAD than those obtained from AC images. Patients with no prior CAD history with TPDS score higher than 5 in MPS should be referred for CA with priority.

Keywords: Myocardial perfusion imaging, SPECT/CT, coronary angiography
\end{abstract}

\section{Öz}

Amaç: Bu çalışmada miyokard perfüzyon sintigrafisinin (MPS) kantitatif değerlendirilmesiyle koroner anjiyografi (KAG) yapılacak hastalarının seçiminde en önemli perfüzyon skorunun belirlenmesi amaçlandı.

Yöntem: Aralık 2017-Ocak 2019 tarihleri arasında kliniğimizde MPS tek foton emisyon tomografisi/bilgisayarlı tomografi (SPECT/BT) görüntüleme uygulanan ve daha önce koroner arter hastalığı $(\mathrm{KAH})$ tanısı bulunmayan ve MPS sonrası KAG yapılan hastalar çalışmaya dahil edildi. KAG sonucunda en az bir koroner damarda \%70 veya daha fazla darlık izlenen hastalar koroner arter darlığı (KAD) açısından pozitif kabul edildi. Seksen hastanın atenüasyon düzeltilmemiş (NC) ve SPECT/BT ile atenüasyon düzeltilmiş (AC) görüntülerden elde edilen toplam stres skoru, toplam rest skoru, toplam perfüzyon bozukluğu ve extent puanları Mann-Whitney $U$ testi ile değerlendirildi. $P<0,05$ değeri anlamlı kabul edildi. Alıı işlem karakteristikleri (ROC) analizi yapıldı.

Address for Correspondence: Nazlı Pınar Karahan Şen MD, Dokuz Eylül University Faculty of Medicine, Department of Nuclear Medicine, İzmir, Turkey Phone: +90 2324124290 E-mail: drpinarkarahan@hotmail.com ORCID ID: orcid.org/0000-0002-1562-9085 Received: 15.02.2021 Accepted: 03.07.2021 
Bulgular: NC ve AC görüntülerinden elde edilen skorlar, ExtentRac ve TPDRac dışındaki tüm skorlar için iki grup arasında anlamlı fark görüldü. ROC eğrilerindeki en yüksek tanı değeri NC görüntülerinden elde edilen TPDS değeri olarak belirlendi (eğrinin altında kalan alan: 0,880, \%95 güven aralı̆̆ı, 0,807-0,952, p<0,001). TPDS için ROC eğrisinden elde edilen kesim değeri 5,5 olarak bulundu.

Sonuç: NC görüntülerden elde edilen skorların AC görüntülerden elde edilen skorlara göre daha fazla KAD saptama gücü vardır. Daha önceden bilinen KAH olmayan ve MPS'de TPDS skoru 5'in üzerinde olan hastalar KAG'ye öncelikli olarak yönlendirilmelidir.

Anahtar kelimeler: Miyokard perfüzyon görüntüleme, SPECT/BT, koroner anjiyografi

\section{Introduction}

Coronary artery disease (CAD) is a result of atherosclerosis of coronary arteries, which restricts the heart's blood flow $(1,2)$. Myocardial ischemia can occur, and patients may experience ischemic symptoms like typical angina, depending on the degree of the coronary artery stenosis. Myocardial perfusion scintigraphy (MPS) is one of the frequently used non-invasive diagnostic tests of CAD. An unbalanced cardiac oxygen support mechanism in $C A D$ results in ischemia, which causes a reversible perfusion defect occurring in scintigraphy images (3). Coronary angiography (CA) is the gold standard method for CAD diagnosis. Since it is an invasive and expensive method and carries the mortality risks, selecting patients suitable for CA is important $(4,5)$.

Scanning MPS with computerized tomography (CT) combined with gated single-photon emission computerized tomography (SPECT/CT) is an emerging technique $(6,7)$. CT being part of the SPECT/CT allows attenuation correction from the emission by extracardiac tissues and reduces false positive rates $(8,9,10)$. Both attenuation-corrected (AC) and non-attenuation-corrected (NC) images are obtained from SPECT/CT. MPS is currently interpreted as ischemia positive or negative according to the presence of a reversible perfusion defect. Alternatively, several scores obtained from scintigraphy images depict ischemia severity or extent, such as summed stress score (SSS), rest score (SRS), and differential score (SDS); total perfusion deficit (TPD); and extent of the defect $(11,12,13)$. While scores are calculated using automatic programs, each image requires comparison with its own normal data; therefore, scores from $A C$ and $N C$ images may differ. The question is that which score is valuable or do the scores have advantages over each other? We investigated patients who underwent MPS and subsequently CA. We evaluated the mentioned perfusion scores obtained from $\mathrm{AC}$ and $\mathrm{NC}$ images to identify these scores' relation with CA results and to determine the cut-off value for the most relevant score.

\section{Materials and Methods}

\section{Study Design}

This study was designed as a retrospective study.

\section{Study Population}

Patients who underwent MPS between November 2017 and February 2020 at our institution were retrospectively evaluated. Those without prior CAD history and underwent CA recently (in $>6$ months) after MPS were included in this study, which was approved ethically at our institution (Dokuz Eylül University Non-interventional Research Ethics Committee protocol number: 5448-GOA, decision number: 01.06.2020, 2020/11-06).

\section{Study Protocol}

Patients underwent a 1-day rest/stress or 2-day stress/ rest MPS protocol. MPSs were performed using a SPECT/ CT scanner (GE Healthcare). Patients discontinued betablockers and calcium channel blockers $48 \mathrm{~h}$ before the study, and nitrate derivative drugs were stopped for $24 \mathrm{~h}$. Following a 6-h fasting period, MPS was performed. In the 1-day protocol rest, images were obtained $1 \mathrm{~h}$ after the injection of 8 millicuries (mCi) technetium-99m methoxyisobutyl-isonitrile (Tc-99m-MIBI). Three hours after the rest procedure, exercise stress tests were performed on a treadmill following the BRUCE protocol. Those who could not tolerate exercise stress test, pharmacological stress test was applied with adenosine. The dobutamine stress test was preferred if the patient had dyspnea and could not tolerate the treadmill. Patients who reached $85 \%$ of the target heartbeat [(220 - age in years) $\times 85 \%$ ] were included in the study. Stress images were obtained 30 min after $22 \mathrm{mCi}$ of Tc-99m-MIBI was injected. On the first day of the 2-day protocol, patients were imaged after stress protocol with 22-mCi activity; then on another day, rest procedures were done with $22 \mathrm{mCi}$ of Tc-99m-MIBI. Because both protocols have equal diagnostic value, their MPS images were included in the study (8). Patients with prior CAD history and inadequate stress test were excluded. Consequently, 80 patients were included in the study.

Rest and stress images were processed and quantitatively assessed using the Xeleris and Quantitative Perfusion SPECT (QPS) program based on a 20-segment scoring model. QPS gives scores automatically using a five-point scoring system according to the radiopharmaceutical uptake degree $(0$, normal; 1 , mildly decreased; 2 , moderately decreased; 3 , severely decreased; and 4, 
absence of segmental uptake) in both images. SSS, SRS, SDS, TPD, and extent values from rest (TPDR, ExtentR) and stress (TPDS, ExtentS) images are the scores automatically derived from the images. SSS and SRS provide information about hipoperfusion areas and the degree of perfusion deficient of stress and rest images, respectively. SDS is the difference between SSS and SRS. TPD represents the extent and severity of the perfusion defect. The scores obtained from NC (SSS, SRS, SDS, TPDR, TPDS, ExtentR, ExtentS) and AC images (SSSac, SRSac, SDSac, TPDRac, TPDSac, ExtentRac, ExtentSac) were recorded. In addition to the quantitative analysis of MPS, patients' CA reports were retrospectively evaluated. A significant $C A D$ was determined as $\geq 70 \%$ stenosis of at least one coronary artery (left anterior descending artery, left circumflex artery, and right coronary artery) or $\geq 50 \%$ narrowing in the left main coronary artery (14).

\section{Statistical Analysis}

Statistical Package for the Social Sciences software version 24.0 for Windows was used to analyze the data. CA results; SSS, SRS, SDS, TPDS, and TPDR; and ExtentS and ExtentR scores from $A C$ and NC images were evaluated using the Mann-Whitney $U$ test. A $p$ value of $<0.05$ was considered as significant. Receiver operating characteristic (ROC) analyses were performed for the scores. An area under the curve (AUC) of $>0.5$ was accepted as worthwhile. A cut-off value was obtained from the score with the highest AUC.

\section{Results}

Fifty-one patients were female and 29 were male, with mean age of $60.4 \pm 12.4$ years (32-89 years). Among the 80 patients, 32 were CAD-positive, with mean scores detected as SSS, 13.53 (3-43); SRS, 6.00 (0-36); SDS, 6.90 (0-29); ExtentR, 10.18 (0-49); TPDR, 8.90 (1-44); ExtentS, 17.96 (348); TPDS, 14.87 (4-41); SSSac, 13.62 (2-40); SRSac, 5.15 (0-29); SDSac, 8.15 (2-19); ExtentRac, 7.28 (0-37); TPDRac, 6.34 (0-33); ExtentSac, 18.12 (0-49); and TPDSac, 14.15 (0-38). The mean range of all scores derived from both images was significantly higher in the CAD-positive group than the CAD-negative group $(p<0.05)$ except TPDRac and ExtentRac. The results are demonstrated in Table 1. ROC analyses demonstrated that, for AC and NC images, both TPDS have the highest AUC value among the scores (0.817 and 0.880, TPDSac and TPDS, respectively). Also, AUC values of the scores from NC images were detected at higher values than those from $A C$ images. Among all scores, TPDS derived from NC images was determined as having the highest AUC value (AUC: 0.880) (Table 2). According to the Youden index with $84.4 \%$ sensitivity and $75 \%$ specificity, the ROC curve analysis of TPDS derived from NC images provided a 5.5 cut-off value in predicting CAD (Figures 1, 2, 3)

\section{Discussion}

Our study results demonstrated the usefulness of the MPS quantitative scores in detecting significant CAD. The scores

\section{Table 1. Univariate analysis results of the scores using the Mann-Whitney $U$ test}

\begin{tabular}{|c|c|c|c|c|c|}
\hline & All patients' mean $(n=80)$ & CA $(-)$ mean $(n=48)$ & CA $(+)$ mean $(n=32)$ & $p$ value & AUC \\
\hline SSS & $8.17(0-43)$ & $4.60(0-19)$ & $13.53(3-43)$ & 0.000 & 0.855 \\
\hline SRS & $3.40(0-36)$ & $1.66(0-11)$ & $6.00(0-36)$ & 0.000 & 0.735 \\
\hline SDS & $4.47(0-29)$ & $2.85(0-10)$ & $6.90(0-29)$ & 0.000 & 0.764 \\
\hline ExtentR & $6.77(0-49)$ & $4.50(0-27)$ & $10.18(0-49)$ & 0.027 & 0.646 \\
\hline TPDR & $6.07(0-44)$ & $4.18(0-21)$ & $8.90(1-44)$ & 0.004 & 0.691 \\
\hline ExtentS & $10.16(0-48)$ & $4.95(0-26)$ & $17.96(3-48)$ & 0.000 & 0.873 \\
\hline TPDS & $8.75(0-41)$ & $4.66(0-21)$ & $14.87(4-41)$ & 0.000 & 0.880 \\
\hline SSSac & $8.81(0-40)$ & $5.60(0-27)$ & $13.62(2-40)$ & 0.000 & 0.788 \\
\hline SRSac & $2.91(0-29)$ & $1.41(0-11)$ & $5.15(0-29)$ & 0.001 & 0.715 \\
\hline SDS ac & $5.72(0-19)$ & $4.10(0-16)$ & $8.15(2-19)$ & 0.000 & 0.741 \\
\hline ExtentRac & $5.78(0-37)$ & $4.79(0-34)$ & $7.28(0-37)$ & 0.346 & 0.562 \\
\hline TPDRac & $5.20(0-33)$ & $4.43(0-26)$ & $6.34(0-33)$ & 0.258 & 0.575 \\
\hline ExtentSac & $10.76(0-49)$ & $5.85(0-36)$ & $18.12(0-49)$ & 0.000 & 0.816 \\
\hline TPDSac & $8.67(0-38)$ & $5.02(0-24)$ & $14.15(0-38)$ & 0.000 & 0.817 \\
\hline
\end{tabular}

AC: Attenuation-corrected, AUC: Area under curve, CA (-): Coronary angiography negative, CA (+): Coronary angiography positive, Cl: Confidence interval, ExtentR: Extent rest, ExtentS: Extent stress, n: Number of patients, SDS: Summed differential score, SRS: Summed rest score, SSS: Summed stress score, TPDR: Total perfusion deficit rest, TPDS: Total perfusion deficit stress 


\begin{tabular}{|c|c|c|c|c|c|}
\hline Score & AUC & $p$ & Sensitivity & Specificity & Cut-off \\
\hline SSS & $0.855(0.775-0.935,95 \% \mathrm{Cl})$ & 0.000 & $90.6 \%$ & $70.8 \%$ & 4.5 \\
\hline SRS & $0.735(0.623-0.846,95 \% \mathrm{Cl})$ & 0.000 & $84.4 \%$ & $58.3 \%$ & 0.5 \\
\hline SDS & $0.764(0.656-0.871,95 \% \mathrm{Cl})$ & 0.000 & $59.4 \%$ & $83.3 \%$ & 4.5 \\
\hline ExtentR & $0.646(0.519-0.772,95 \% \mathrm{Cl})$ & 0.028 & $50 \%$ & $77.1 \%$ & 6.5 \\
\hline TPDR & $0.691(0.574-0.809,95 \% \mathrm{Cl})$ & 0.004 & $50 \%$ & $81.3 \%$ & 6.5 \\
\hline Extents & $0.873(0.798-0.948,95 \% \mathrm{Cl})$ & 0.000 & $90.6 \%$ & $70.8 \%$ & 5.5 \\
\hline TPDS & $0.880(0.807-0.952,95 \% \mathrm{Cl})$ & 0.000 & $84.4 \%$ & $75 \%$ & 5.5 \\
\hline SSSac & $0.788(0.691-0.886,95 \% \mathrm{Cl})$ & 0.000 & $71.9 \%$ & $72.9 \%$ & 7.5 \\
\hline SRSac & $0.715(0.598-0.832,95 \% \mathrm{Cl})$ & 0.001 & $75 \%$ & $60.4 \%$ & 0.5 \\
\hline SDS ac & $0.741(0.635-0.847,95 \% \mathrm{Cl})$ & 0.000 & $100 \%$ & $41.7 \%$ & 1.5 \\
\hline ExtentRac & $0.562(0.429-0.694,95 \% \mathrm{Cl})$ & 0.351 & $40.6 \%$ & $77.1 \%$ & 6.5 \\
\hline TPDRac & $0.575(0.445-0.704,95 \% \mathrm{Cl})$ & 0.261 & $21.9 \%$ & $95.8 \%$ & 11.5 \\
\hline ExtentSac & $0.816(0.723-0.910,95 \% \mathrm{Cl})$ & 0.000 & $81.3 \%$ & $72.9 \%$ & 5.5 \\
\hline TPDSac & $0.817(0.723-0.912,95 \% \mathrm{Cl})$ & 0.000 & $75 \%$ & $79.2 \%$ & 7.5 \\
\hline
\end{tabular}
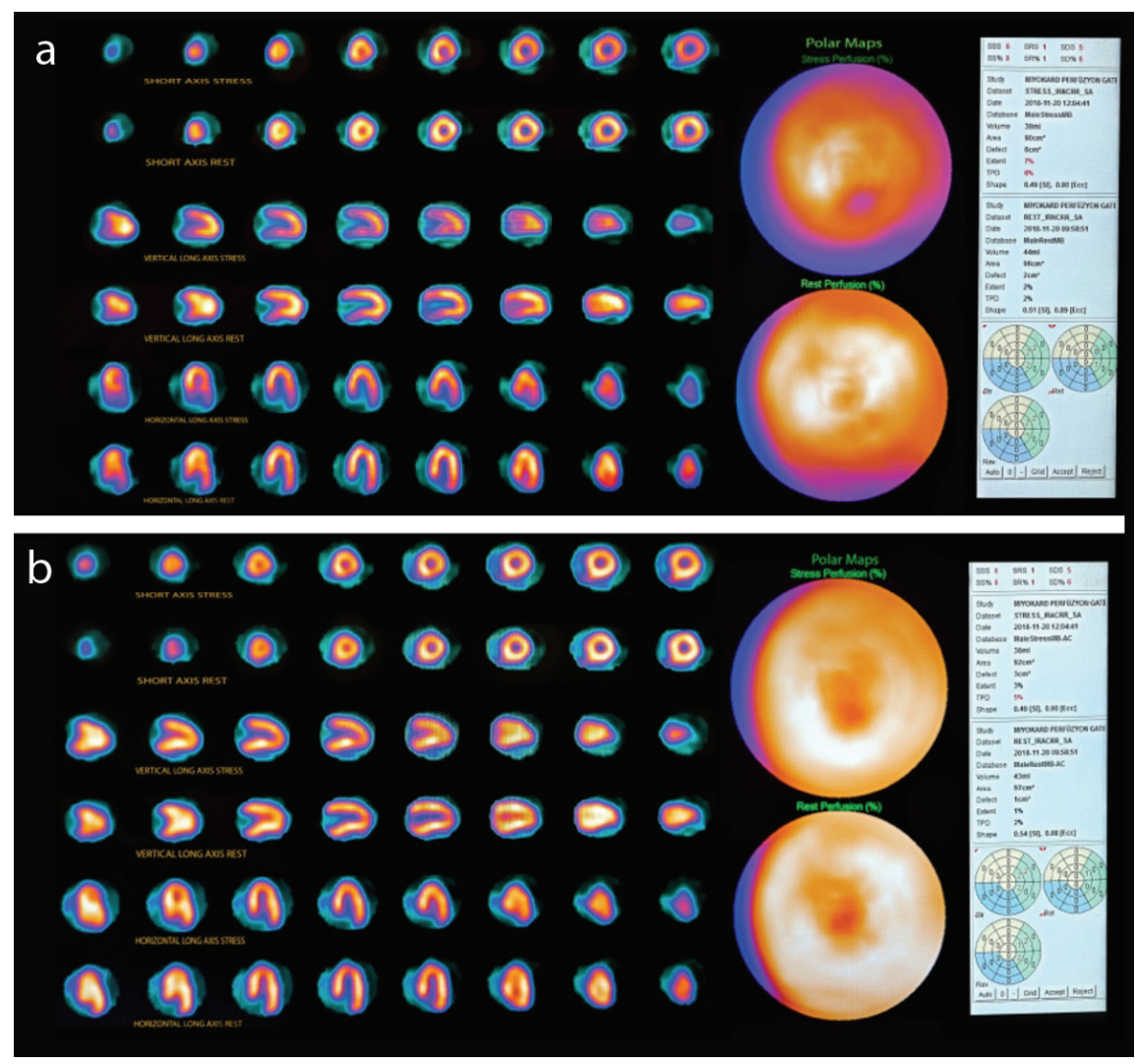

Figure 1. NC (a) and AC (b) MPS images of a 65-year-old male patient. The patient's TPDS and TPDSac scores are $6 \%$ and $5 \%$. The patient is CAD positive according to NC images but negative in AC images. Angiography results demonstrated $>70 \%$ narrowing in the LAD and RCA

LAD: Left anterior descending artery, RCA: Right coronary artery, NC: Non-attenuation-corrected, AC: Attenuation-corrected, MPS: Myocardial perfusion scintigraphy, CAD: Coronary artery disease 
obtained from both images were evaluated with the CA results. It was detected that the scores from NC images have higher AUC values than those from the AC images. Furthermore, while TPDS scores demonstrated the highest significance in both images, TPDS from NC images has the highest discriminative values to detect significant $C A D$ among the scores.

MPS is a diagnostic imaging method in which quantitative data can be obtained using programs allowing image comparison with normal data in memory using an automatic scoring system. SSS, SRS, and SDS and TPD scores are derived automatically from the segmentation of perfusion maps. Various studies have been conducted to obtain an MPS diagnostic value by comparing the main scores obtained from the polar map with methods, such as CA, fractional flow reserve, or CT angiography $(15,16,17,18)$.

One of the major deficiencies in planar images is imaging artifacts, occurring due to patient motion, photon attenuation (breast attenuation in women and diaphragmatic attenuation in men), or extracardiac activity in the region of interest. They could mimic true abnormalities, and artifacts could be challenging while interpreting the reports (19). The widespread SPECT/CT use to prevent attenuation artifacts increased the use of AC images in MPS interpretation $(20,21)$. The evaluation of $A C$ images is similar to $N C$ images, but the interpreting physician should be familiar with the AC images (22). Quantitative evaluation of the images plays an important role in the interpretation. It is recommended to report the defect's extent and severity. The scores obtained from both images could be different from each other. Therefore, knowing the difference between the scores is important to predict CAD using quantitative analyses. There are studies with different results in this regard $(23,24,25,26)$. In a study, which evaluated the scores from both images (17), ROC analysis results were similar to our study. For SSS, SDS, and TPDS from NC images, AUC values were minimally higher than the scores obtained from AC images. Similarly, TPDS from NC images (AUC: 0.87 ) has the highest $A \cup C$ to detect significant $C A D$. Xu et al. (21) reported similar AUC (0.87) values in their study for TPD from both images. On the other hand, a study compared automatic and visual evaluation of MPS.
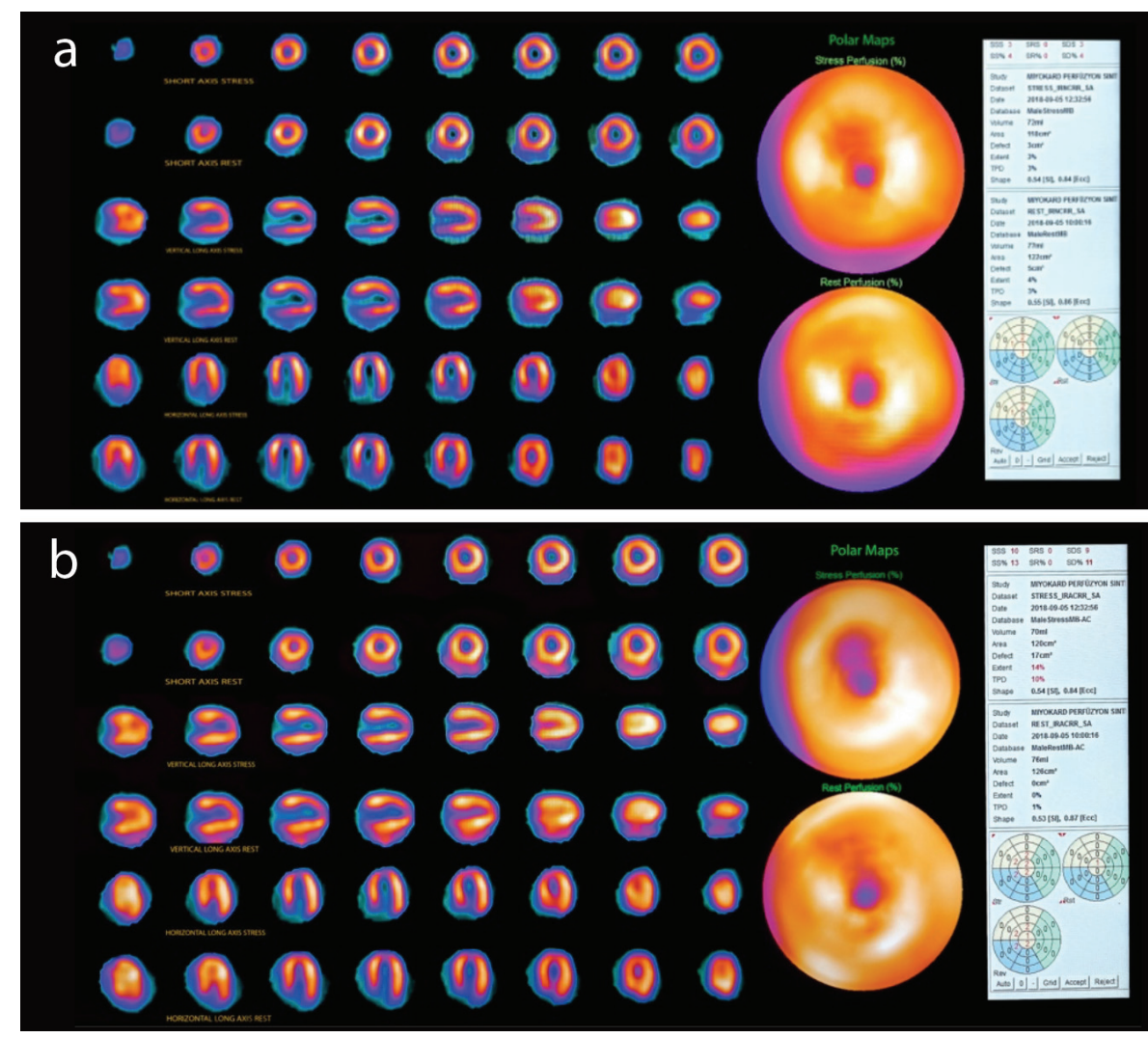

Figure 2. NC (a) and AC (b) MPS images of a 54-year-old male patient. TPDS and TPDSac scores were $3 \%$ and $10 \%$. The patient is CAD negative according to NC images but positive in AC images. Angiography results were found to be normal

NC: Non-attenuation-corrected, AC: Attenuation-corrected, MPS: Myocardial perfusion scintigraphy, TPDS: Total perfusion deficit stress, CAD: Coronary artery disease 
a

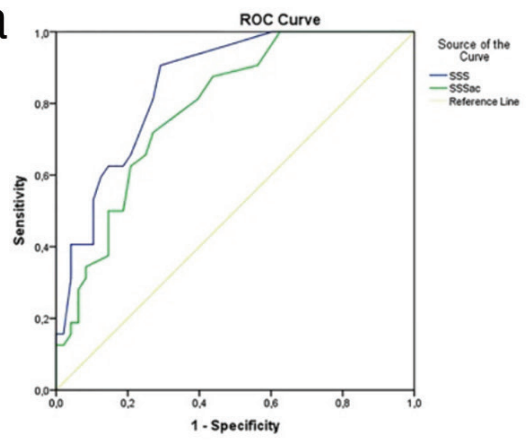

b
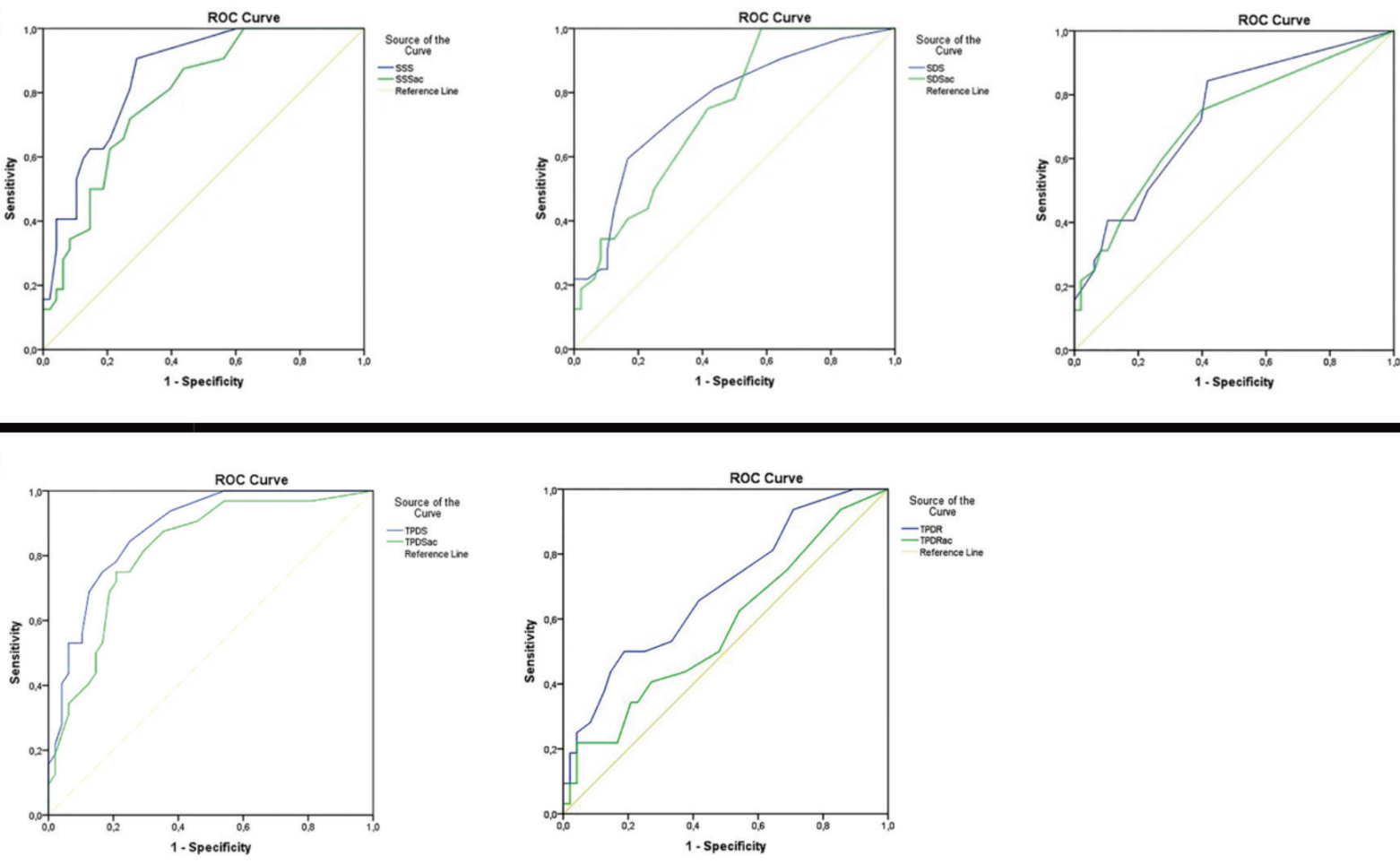

Source of the
Cunve

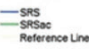

Source of the
Cunie

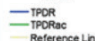
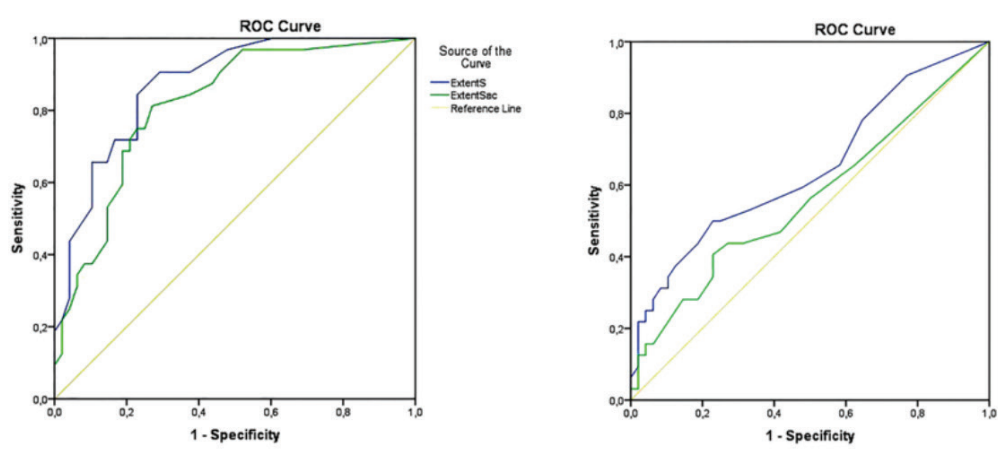

\section{C}
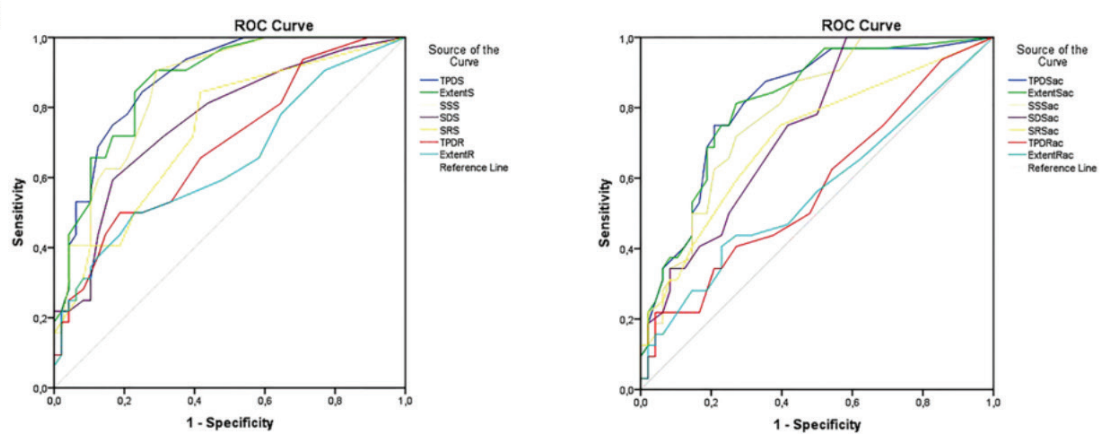

Figure 3. ROC curves of the scores: SSS, SDS, and SRS (a); TPDS, TPDR, ExtentS, and ExtentR (b); and all scores in one curve (c). Both scores obtained from $A C$ and NC images were demonstrated

ROC: Receiver operating characteristic, SDS: Summed differential score, SRS: Summed rest score, SSS: Summed stress score, TPDS: Total perfusion deficit stress, TPDR: Total perfusion deficit rest, NC: Non-attenuation-corrected, AC: Attenuation-corrected 
Arsanjani et al. (26) demonstrated a higher AUC value for TPD score from AC images in detecting significant CAD from our results (AUC: 0.92 with $84 \%$ sensitivity and $88 \%$ specificity) and detected AUC of 0.91 for TPD score from NC images with $83 \%$ sensitivity and a higher specificity than our results ( $81 \%$ vs. $75 \%)$. Unlike our study, they suggest scores from AC images were found to have more diagnostic power than those from NC images. Also, none of these studies mentioned of determining a cut-off value for TPD.

A study evaluated coronary vessels separately, with cut-off values determined as 8.5, 4.5, and 3.5 for TPD stress, rest, and difference, respectively (15). Another study determined cut-off values as $\geq 5.5$ (SSS), $\geq 2.5$ (SDS), and $\geq 9.5$ (TPDS) to predict significant CAD (16). The AUC sensitivity and specificity values calculated for the TPD scores of our study were found to be higher than those in these studies. This difference is thought to be due to the results, which can be changed according to the processes or artifacts like motion.

There are studies related to SSS and SDS $(21,27,28)$. Some studies suggest that SDS above 1 is an evaluable finding favoring ischemia, and some suggest a cut-off value $\geq 2$ for SDS to determine $\operatorname{CAD}(21,27)$. Also, it has been reported that SSS above 4 increases the risk of cardiac events (28). However, the reproducibility of differential scores is accepted to be lower. SSS $>4$ was demonstrated to significant CAD with $86 \%$ sensitivity and $82 \%$ specificity, similar to our results (90.6\% sensitivity, $70.8 \%$ specificity, SSS cut-off value of 4.5) (29).

The use of TPD value provides a quantitative evaluation and contributes to the visual evaluation, increasing reproducibility and reducing interobserver variability (30). TPD with $\geq 5 \%$ threshold was accepted for patients to undergo coronary intervention in the COURAGE study (31). However, there are studies suggesting a slightly higher TPD threshold (>7\%) in MPS to detect significant ischemia. Our study demonstrates that the majority of true positive patients in MPS (84.4\%) had a TPD score from NC images $\geq 5$. 5 . These findings suggested that, if TPDS score in patients referred for MPS is $>5$, CA results are high, probably positive in terms of severe CAD in at least one coronary artery.

Using $\mathrm{CT}$, a patient's low-dose extra radiation exposure could be seen as a minimal disadvantage of AC images (32). Nevertheless, studies have reported that AC image addition to the NC data improves significant CAD diagnosis. In visual evaluation, both images together provide better results than NC images only (AUC: 0.90 vs. 0.87 ) in determining CAD (26). Particularly, AC images are known to be successful in the correction of artifacts from attenuation (33). Superior advantages can be obtained in the visual evaluation by providing attenuation evaluation with SPECT/CT imaging. However, this is not the case in quantitative evaluation. Conversely, in our study, the scores from images without any $A C$ have more power to detect $C A D$, which may be due to the compared databases or manual processes needed from attenuation images. These processes could reduce reproducibility.

\section{Study Limitations}

The retrospective design and limited number of patients are the study's main limitation.

\section{Conclusion}

Considering TPDS before CA may help select patients who need CA primarily. Patients with no prior CAD history with TPDS score $>5$ in MPS should be primarily advised for CA. Although the MPS evaluation from AC images has become widespread recently, according to this study's quantitative evaluation results, the scores obtained from non-corrected images have more power to detect CAD than the scores obtained from AC images.

\section{Ethics}

Ethics Committee Approval: Dokuz Eylül University Noninterventional Research Ethics Committee protocol number: 5448-GOA, decision number: 01.06.2020, 2020/11-06).

Informed Consent: Retrospective cross sectional study.

Peer-review: Externally and internally peer-reviewed.

\section{Authorship Contributions}

Surgical and Medical Practices: N.P.K.Ş., R.B., B.Ş., B.A., Concept: N.P.K.Ş., R.B., Design: N.P.K.Ş., R.B., Data Collection or Processing: N.P.K.Ş., Analysis or Interpretation: N.P.K.Ş., R.B., Literature Search: N.P.K.Ş., R.B, Writing: N.P.K.Ş., R.B.

Conflict of Interest: No conflict of interest was declared by the authors.

Financial Disclosure: The authors declared that this study has received no financial support.

\section{References}

1. Sanchis-Gomar F, Perez-Quilis C, Leischik R, Lucia A. Epidemiology of coronary heart disease and acute coronary syndrome. Ann Transl Med 2016:4:256

2. Libby P, Theroux P. Pathophysiology of coronary artery disease. Circulation 2005;111:3481-3488.

3. Fathala A. Myocardial perfusion scintigraphy: techniques, interpretation, indications and reporting. Ann Saudi Med 2011;31:625-634.

4. Athanasiou LS, Fotiadis DI, Michalis LK. Atherosclerotic plaque characterization methods based on coronary imaging. 1st Ed. London: Elsevier; 2017. p. 23-28. 
5. Noto TJ Jr, Johnson LW, Krone R, Weaver WF, Clark DA, Kramer JR Jr, Vetrovec GW. Cardiac catheterization 1990: a report of the Registry of the Society for Cardiac Angiography and Interventions (SCA\&I). Cathet Cardiovasc Diagn 1991;24:75-83.

6. Notghi A, Low CS. Myocardial perfusion scintigraphy: past, present and future. Br J Radiol 2011;84:S229-236.

7. Seo Y, Mari C, Hasegawa BH. Technological development and advances in single-photon emission computed tomography/computed tomography. Semin Nucl Med 2008;38:177-198.

8. Czaja M, Wygoda Z, Duszańska A, Szczerba D, Głowacki J, Gąsior M, Wasilewski JP. Interpreting myocardial perfusion scintigraphy using single-photon emission computed tomography. Part 1. Kardiochir Torakochirurgia Pol 2017; 14:192-199.

9. Lecchi M, Malaspina S, Scabbio C, Gaudieri V, Del Sole A. Myocardial perfusion scintigraphy dosimetry: optimal use of SPECT and SPECT/ CT technologies in stress-first imaging protocol. Clin Transl Imaging 2016;4:491-498.

10. Hayes SW, De Lorenzo A, Hachamovitch R, Dhar SC, Hsu P, Cohen I, Friedman JD, Kang X, Berman DS. Prognostic implications of combined prone and supine acquisitions in patients with equivocal or abnormal supine myocardial perfusion SPECT. J Nucl Med 2003;44:1633-1640.

11. Kakhki VRD, Sadeghi R, Torabian-Kakhki M, Rad MP, Sadri K. Semi-quantitative segmental perfusion scoring in myocardial perfusion SPECT: Visual vs. automated analysis. Iranian Journal of Nuclear Medicine 2014;22:64-69.

12. Yoda S, Nakanishi K, Tano A, Hori Y, Suzuki Y, Matsumoto N, Hirayama A. Validation of automated quantification of nuclear cardiology in Japanese patients using total perfusion deficits: Comparison with visual assessment. J Cardiol 2014;63:350-357.

13. Berman DS, Kang X, Gransar H, Gerlach J, Friedman JD, Hayes SW, Thomson LE, Hachamovitch R, Shaw LJ, Slomka PJ, Yang LD, Germano G. Quantitative assessment of myocardial perfusion abnormality on SPECT myocardial perfusion imaging is more reproducible than expert visual analysis. J Nucl Cardiol 2009;16:45-53.

14. Neglia D, Rovai D, Caselli C, Pietila M, Teresinska A, Aguadé-Bruix S, Pizzi MN, Todiere G, Gimelli A, Schroeder S, Drosch T, Poddighe R, Casolo G, Anagnostopoulos C, Pugliese F, Rouzet F, Le Guludec D, Cappelli F, Valente S, Gensini GF, Zawaideh C, Capitanio S, Sambuceti G, Marsico F, Perrone Filardi P, Fernández-Golfín C, Rincón LM, Graner FP, de Graaf MA, Fiechter M, Stehli J, Gaemperli O, Reyes E, Nkomo S, Mäki M, Lorenzoni V, Turchetti G, Carpeggiani C, Marinelli M, Puzzuoli S, Mangione M, Marcheschi P, Mariani F, Giannessi D, Nekolla S, Lombardi M, Sicari R, Scholte AJ, Zamorano JL, Kaufmann PA, Underwood SR, Knuuti J; EVINCI Study Investigators. Detection of significant coronary artery disease by noninvasive anatomical and functional imaging. Circ Cardiovasc Imaging 2015;8:e002179.

15. Doğan C, Bayram Z, Çınaral F, Uslu A, Acar R, Önal Ç, Çap M, Güvendi B, Unkun T, Karaduman A, Hakgör A, Akbal ÖY, Kaymaz C, Özdemir N. Effect of localization of coronary artery lesions on total perfusion deficit in myocardial perfusion scintigraphy. Kosuyolu Heart Journal 2018;21:181-186.

16. Doğan C, Çınaral F, Karagöz A, Bayram Z, Önal SÇ, Candan Ö, Acar RD, Çap M, Erdoğan E, Hakgör A, Akbal ÖY, Uslu A, Kaymaz C, Özdemir $\mathrm{N}$. Comparison of automated quantification and semiquantitative visual analysis findings of IQ SPECT MPI with conventional coronary angiography in patients with stable angına. Turk Kardiyol Dern Ars 2019;47:357-364

17. Driessen RS, Raijmakers PG, Danad I, Stuijfzand WJ, Schumacher SP, Leipsic JA, Min JK, Knuuti J, Lammertsma AA, van Rossum AC, van Royen $\mathrm{N}$, Underwood SR, Knaapen P. Automated SPECT analysis compared with expert visual scoring for the detection of FFR-defined coronary artery disease. Eur J Nucl Med Mol Imaging 2018;45:1091-1100.

18. Min JK, Koduru S, Dunning AM, Cole JH, Hines JL, Greenwell D, Biga C, Fanning G, LaBounty TM, Gomez M, Horowitz JM, Hadimitzsky M, Hausleiter J, Callister TQ, Rosanski AR, Shaw LJ, Berman DS, Lin FY. Coronary $\mathrm{CT}$ angiography versus myocardial perfusion imaging for near- term quality of life, cost and radiation exposure: a prospective multicenter randomized pilot trial. J Cardiovasc Comput Tomogr 2012;6:274-283.

19. Allie R, Hutton BF, Prvulovich E, Bomanji J, Michopoulou S, Ben-Haim S. Pitfalls and artifacts using the D-SPECT dedicated cardiac camera. J Nucl Cardiol 2016;23:301-310.

20. Chen J, Caputlu-Wilson SF, Shi H, Galt JR, Faber TL, Garcia EV. Automated quality control of emission-transmission misalignment for attenuation correction in myocardial perfusion imaging with SPECT-CT systems. J Nucl Cardiol 2006;13:43-49.

21. Xu Y, Fish M, Gerlach J, Lemley M, Berman DS, Germano G, Slomka PJ. Combined quantitative analysis of attenuation corrected and noncorrected myocardial perfusion SPECT: Method development and clinical validation. J Nucl Cardiol 2010;17:591-599.

22. Holly TA, Abbott BG, Al-Mallah M, Calnon DA, Cohen MC, DiFilippo FP, Ficaro EP, Freeman MR, Hendel RC, Jain D, Leonard SM, Nichols KJ, Polk DM, Soman P; American Society of Nuclear Cardiology. Single photonemission computed tomography. J Nucl Cardiol 2010;17:941-973.

23. Huang JY, Huang CK, Yen RF, Wu HY, Tu YK, Cheng MF, Lu CC, Tzen KY, Chien KL, Wu YW. Diagnostic Performance of Attenuation-Corrected Myocardial Perfusion Imaging for Coronary Artery Disease: A Systematic Review and Meta-Analysis. J Nucl Med 2016;57:1893-1898.

24. Sharma P, Patel CD, Karunanithi S, Maharjan S, Malhotra A. Comparative accuracy of $C T$ attenuation-corrected and non-attenuation-corrected SPECT myocardial perfusion imaging. Clin Nucl Med 2012;37:332-338.

25. Genovesi D, Giorgetti A, Gimelli A, Kusch A, D'Aragona Tagliavia I, Casagranda M, Cannizzaro G, Giubbini R, Bertagna F, Fagioli G, Rossi M, Romeo A, Bertolaccini P, Bonini R, Marzullo P. Impact of attenuation correction and gated acquisition in SPECT myocardial perfusion imaging: results of the multicentre SPAG (SPECT Attenuation Correction vs Gated) study. Eur J Nucl Med Mol Imaging 2011;38:1890-1898.

26. Arsanjani $R, X u Y$, Hayes SW, Fish M, Lemley M Jr, Gerlach J, Dorbala S, Berman DS, Germano G, Slomka P. Comparison of fully automated computer analysis and visual scoring for detection of coronary artery disease from myocardial perfusion SPECT in a large population. J Nucl Med 2013;54:221-228.

27. Danias PG, Papaioannou Gl, Ahlberg AW, O'Sullivan DM, Mann A, Boden WE, Heller GV. Usefulness of electrocardiographic-gated stress technetium-99m sestamibi single-photon emission computed tomography to differentiate ischemic from nonischemic cardiomyopathy. Am J Cardiol 2004;94:14-19.

28. Lindner $\mathrm{O}$, Rusche $H$, Schäfers M, Schober O. Myocardial perfusion SPECT: current concepts. Burchert Dtsch Arztebl 2007;104:A952-958.

29. Slomka PJ, Nishina H, Berman DS, Akincioglu C, Abidov A, Friedman JD, Hayes SW, Germano G. Automated quantification of myocardial perfusion SPECT using simplified normal limits. J Nucl Cardiol 2005;12:66-77.

30. Slomka P, Xu Y, Berman D, Germano G. Quantitative analysis of perfusion studies: strengths and pitfalls. J Nucl Cardiol 2012;19:338-346.

31. Shaw LJ, Berman DS, Maron DJ, Mancini GB, Hayes SW, Hartigan PM, Weintraub WS, O'Rourke RA, Dada M, Spertus JA, Chaitman BR, Friedman J, Slomka P, Heller GV, Germano G, Gosselin G, Berger P, Kostuk WJ, Schwartz RG, Knudtson M, Veledar E, Bates ER, McCallister B, Teo $\mathrm{KK}$, Boden WE; COURAGE Investigators. Optimal medical therapy with or without percutaneous coronary intervention to reduce ischemic burden: results from the Clinical Outcomes Utilizing Revascularization and Aggressive Drug Evaluation (COURAGE) trial nuclear substudy. Circulation 2008;117:1283-1291

32. Wells RG, Trottier M, Premaratne M, Vanderwerf $K$, Ruddy TD. Single CT for attenuation correction of rest/stress cardiac SPECT perfusion imaging. J Nucl Cardiol 2018;25:616-624.

33. Tawakol AE, Tantawy HM, Elashmawy RE, Abdelhafez YG, Elsayed YM. Added Value of CT Attenuation Correction and Prone Positioning in Improving Breast and Subdiaphragmatic Attenuation in Myocardial Perfusion Imaging. J Nucl Med Technol 2021;49:23-29. 